\title{
Development and Performance Evaluation of Indigenously Made Cooling Chambers for Extending the Shelf Life of Mangoes and Sweet Oranges
}

\author{
Debele Debela, Fekadu Lemessa* and H. Ravishankar \\ Department of Food Sciences and Post Harvest Technology, Haramaya University, P O Box 138, Dire Dawa, \\ Ethiopia
}

\begin{abstract}
A study was conducted to develop, construct and evaluate the performance of cooling chambers made from factory pressed burnt clay (structure-1), locally molded mud blocks (structure-2) and wood wall (structure-3) for extending the shelf life of mangoes and sweet oranges. It was observed that structure-1 significantly $(\mathrm{p} \leq 0.05)$ registered low temperature and high relative humidity over structure-2 and structure- 3 . Significant lower physiological loss $(\mathrm{p} \leq 0.05)$ in weight (PLW) was observed in commodities stored under structure-1 due to the low temperature and high RH probably arising from the low vapor pressure. Structure-2 registered significantly $(\mathrm{p} \leq 0.05)$ low PLW as compared to structure-3 attributable to the differences in wall thickness. Total soluble solids increased as storage time progressed. The rate of increment, however, was significantly lower in mangoes stored under structure-1 as compared to the other chambers. The juice content of the commodities decreased over time irrespective of cooling chambers. The rate of reduction in juice content was, however; significantly lower in structure-1 than the other two.
\end{abstract}

Keywords: Cooling-Chamber; Mango; Shelf-life; Sweet-Orange

\section{Introduction}

In Ethiopia, the post-harvest losses of some horticultural commodities at state farms and peasant sectors are estimated to be around 25-30 per cent (Celis and Stenning, 1997). Thus, reducing post-harvest losses through adoption of appropriate post-harvest technologies may result in increased food supply. As far as storage of fruits and vegetables is concerned, hardly any cost-effective significant attempt had been made in Ethiopia in the past to improve farmer's traditional practices of on-farm handling and storage. Under tropical conditions, through the adoption of appropriate evaporative cooling technology, it is possible to a certain extent, to manipulate the temperature and relative humidity, inside a given storage environment which are important factors influencing post-harvest life of horticultural commodities. It is a natural way of cooling the commodity by evaporation of water. The concept of evaporative cooling works through a process, when the air is not saturated (very low relative humidity) and as a consequence, it evaporates the water used for cooling and thus lowers the temperature of the air and the surface in contact. Evaporative cooling technology thus appears to have immense adaptability potential under Ethiopian conditions as it could be established even in remote areas on small and marginal holdings to provide low-cost storage facilities. Accordingly, the present study aimed at development and performance evaluation of indigenously made cooling chambers for extending the shelf-life of mangoes and sweet-oranges, which are the most commonly grown fruit crops in Ethiopia.

\section{Materials and Methods}

\subsection{Structural Construction}

Three different types of cooling chambers of dimensions (61 X 127 X 330) cm were developed and constructed using locally available raw materials viz., wood, factory pressed burnt clay and locally molded mud blocks. Accordingly, the cooling chambers were constructed in triplicate as outlined below:

Structure-1 = Cooling chamber made with factory pressed burnt clay. This represented evaporative cooling chamber technology.

Structure-2 = Cooling chamber made with locally molded mud blocks.

Structure-3 = Cooling chamber prepared with wooden walls representing the control.

All cooling chambers were uniformly provided with a concrete floor and thatch roof coverings. Structure-1 and structure-2 comprised of double walls of $7.5 \mathrm{~cm}$ cavity space, which was filled uniformly with river bed sand ( $2 \mathrm{~mm}$ thick). Structure- 3 was plastered with mud on both internal and external surfaces. The top of each cooling chamber was provided with thatch roof made of eucalyptus and bamboo frames laced with dry grass cover. The tops of the cooling chambers were kept moist uniformly throughout the period of study. Since the crates required to be stacked by a person, a suitable height of $61 \mathrm{~cm}$ was selected. Twenty wooden crates each of dimension ( $34 \times 33 \times 52) \mathrm{cm}$ were stacked one above the other in two parallel rows and columns spaced between $20 \mathrm{~cm}$ and $6 \mathrm{~cm}$ respectively. 


\subsection{Experimental Design}

The experimental design adopted was factorial completely randomized design (CRD) with three replications for the analysis of average temperature and relative humidity (Gomez et al., 1984). The CRD experimental design with three replications for the entire cooling chamber $\mathrm{x}$ time combination of the treatments was realized and was arranged as indicated inTable1.

Table 1. Treatment-time combinations adopted over storage period of Mangoes and sweet Oranges

\begin{tabular}{|c|c|c|}
\hline Cooling chambers & Mangoes & Sweet Oranges \\
\hline 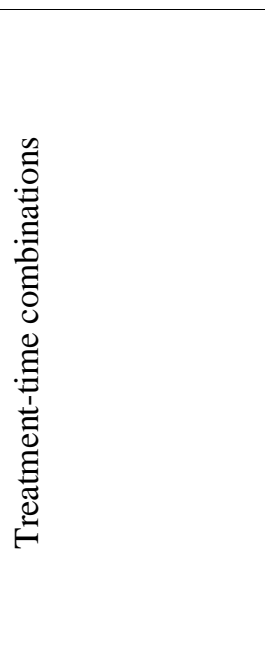 & $\begin{array}{ll}\text { Structure-1 } & \text { 0 Days } \\
\text { Structure-1 } & \text { 3 Days } \\
\text { Structure-1 } & \text { 6 Days } \\
\text { Structure-1 } & \text { 9 Days } \\
\text { Structure-1 } & \text { 12* Days } \\
\text { Structure-2 } & \text { 0 Days } \\
\text { Structure-2 } & \text { 3 Days } \\
\text { Structure-2 } & \text { 6 Days } \\
\text { Structure-2 } & 9 * \text { Days } \\
\text { Structure-3 } & \text { 0 Days } \\
\text { Structure-3 } & \text { 3 Days } \\
\text { Structure-3 } & \text { 6* Days }\end{array}$ & $\begin{array}{ll}\text { Structure-1 } & \text { 0 Days } \\
\text { Structure-1 } & \text { 7 Days } \\
\text { Structure-1 } & \text { 14 Days } \\
\text { Structure-1 } & \text { 21 Days } \\
\text { Structure-1 } & \text { 28 Days } \\
\text { Structure-1 } & \text { 35 Days } \\
\text { Structure-1 } & 38^{*} \text { Days } \\
\text { Structure-2 } & \text { 0 Days } \\
\text { Structure-2 } & 7 \text { Days } \\
\text { Structure-2 } & \text { 14 Days } \\
\text { Structure-2 } & \text { 21 Days } \\
\text { Structure-2 } & \text { 28* Days } \\
\text { Structure-3 } & \text { 0 Days } \\
\text { Structure-3 } & \text { 7 Days } \\
\text { Structure-3 } & \text { 14 Days } \\
\text { Structure-3 } & \text { 21* Days }\end{array}$ \\
\hline
\end{tabular}

*Indicate threshold level of physiological loss in weight in each cooling chamber.

\subsection{Test Samples}

Two types of fruits, mango and sweet orange were used for evaluating the performance of different cooling chambers at different times. These fruits were selected on the basis of their popularity in terms of consumption both by rural and urban dwellers.

\subsection{Test Procedures}

Freshly harvested mangoes and sweet oranges at optimum stage of physiological maturity were obtained from Melkassa Agricultural Research Center, Ethiopia. The commodities were sorted and thoroughly washed in a stream of cold water, followed by treatment with sodium hypochlorite $(0.1 \%)$. The moisture was drained out, fruits were surface dried and then stored in the cooling chambers of Structure-1, Structure-2 and Structure-3 (control). Before storing the commodities, the entire surface area of structure-1, sand and cover were fully moistened with water using hosepipe. The sand in the interspaces of structure-1 was kept moistened throughout the period of study by watering twice a day in morning and evening. The commodities were assorted into three lots of fifty kilograms each in four stackable-vented plastic containers. Each of these lots was then transferred to the three different cooling chambers/storage structures and covered.

\subsection{Data Collection}

\subsubsection{Physiological Loss in Weight}

The physiological loss in weight in per cent with respect to storage time was computed using the equation suggested by Teledo (1991).

$$
\text { Physiological Loss, in Weight }(\%)=\frac{\mathrm{W}_{1}-\mathrm{W}_{2}}{\mathrm{~W}_{1}} \quad \mathrm{X} 100
$$

Where, $\mathrm{W}_{1}=$ the original weight $(\mathrm{kg})$ of given fruit and vegetable; $\mathrm{W}_{2}=$ weight $(\mathrm{kg})$ of given commodity after periodical intervals of storage time.

\subsubsection{Temperature $\left({ }^{\circ} \mathrm{C}\right)$ and Relative Humidity}

The average daily outside and inside temperatures and relative humidity of the storage structures were recorded on the days of observation and at interval of three days for mangoes and seven days for sweet oranges using ordinary thermometer and hygrometers respectively.

\subsubsection{Total Soluble Solids $\left({ }^{\circ}\right.$ Brix)}

The juice samples obtained from random samples of the respective selected commodities were evaluated for total soluble solids content using hand refractometer and values expressed in terms of ${ }^{0}$ Brix at initial point of storage and at different sampling intervals. 


\subsubsection{Juice Content}

Laboratory juice extractor of the Horticulture Laboratory at Haramaya University was used for juice extraction and the extracted juice volume was measured using a graduated glass cylinder and expressed in milliliter of juice per kilogram of fruit weight $(\mathrm{ml} / \mathrm{kg})$. Juice content was determined at the initial point of storage time and at different sampling intervals as mentioned.

\subsubsection{Shelf life in days}

The shelf life of mangoes and sweet oranges was determined by subjectively judging the criteria of unmarketability parameter such as shriveling and softening of the fruits mainly attributable to physiological loss in weight.

\section{Results and Discussion}

\subsection{Evaluation of Cooling Chambers}

Structure-1 registered significantly $(\mathrm{p} \leq 0.05)$ lower temperature than the other chambers. The range of temperature obtained under different chambers during the period of study ranged from $18-21{ }^{\circ} \mathrm{C}$ for structure$1,19-26{ }^{\circ} \mathrm{C}$ for structure- 2 and $20-28{ }^{\circ} \mathrm{C}$ for structure- 3 (Table 2). Therefore, structure-1 appeared to be more suitable in prolonging the shelf life of mangoes and sweet oranges. Edmund et al. (1957) and Roy et al.(1988) also explained that both plant factors as well as environmental factors such as temperature and relative humidity influenced the rate of respiration. Accordingly, the greater the storage temperature is, the higher would be the heat of respiration leading to lower storage life expectancy.

The relative humidity obtained in the cooling chambers varied significantly $(\mathrm{p} \leq 0.05)$ ranging from $83-90 \%$ in structure- $1,71-82 \%$ for structure- 2 and 59 - $72 \%$ in structure-3. This indicated that structure-1 recorded lower temperature and higher relative humidity values as compared to other two structures (Table 3). Similar observations have been reported by Roy et al. (1988) and Thompson (1992). This appeared to be convenient in extending the shelf life of some high moisture containing (more than 80\%) fresh horticultural commodities.

It is also interesting to note here that there were almost no fluctuations in temperature and relative humidity in structure-1 during the holding time (Table 2 and 3 ) as compared to wide fluctuations observed in the other two structures. This is important from the point of view of safe and effective storage of perishable commodities (ASHRAE, 1962; Burdon, 1997; Toledo, 1991).

In this study, structure- 1 registered $4{ }^{\circ} \mathrm{C}$ and $7{ }^{\circ} \mathrm{C}$ lower temperatures over that of structure- 2 and structure- 3 , respectively (Table 2). This could be attributed to the fact that water in the moistened sand might have assumed the wet bulb temperature, which led to the cooling of storage environment (Murata, 1997; Roy et al., 1988). The relative humidity inside structure-1 was higher by 10 and $21 \%$ over that of structure-2 and structure-3, respectively (Table 3). Humidification of the storage environment perhaps occurred as a result of the vapor pressure exerted by the water of the moistened sand in the interspace of structure-1 being higher than that of the surrounding environment (Anon., 1959; ASHRAE, 1962 and Singh et al., 1988).

The temperature and relative humidity values obtained in structure-3 (control) and structure-2 also varied significantly $(\mathrm{p} \leq 0.05)$ from each other (Table 2 and 3). The decrease in temperature and increase in relative humidity in structure- 2 over structure- 3 was of the order of $3{ }^{\circ} \mathrm{C}$ and $11 \%$, respectively. This might be due to the differences in wall thickness and due to differences in thermal conductivity of the components of structures and presence of sand in the interspace of the structure-2, which served as a slab.

The temperature in the structure- 2 might have reduced due to the barrier of chamber's wall to the flow of heat from outside to the inner part. Here, the thicker composite walls $(12 \mathrm{~cm}$ thick mud block and $7.5 \mathrm{~cm}$ sand in the cavity as a slab) might conserve the low temperature obtained during the night time. In fact, the out side temperature is greater than the relatively low temperature of the inner one. Because of this the heat gradient was towards the inside part of the chamber. But the composite wall of the chamber was used as a barrier for the heat flow. Assuming other factors remain constant for all, total resistance to heat flow is directly proportional to the thickness of the wall components and inversely proportional to the thermal conductivity of the construction materials (Barre et al.,1959). Hence, the mud block chamber temperature was reduced as compared to the wooden wall chamber of thickness about $13 \mathrm{~cm}$. This is corroborated by the findings of (Singh et al., 1988), who observed that the temperature difference of two points through composite walls made up of several materials of different thermal conductivity varied. The differences in thermal conductivity of the component materials of mud block and wooden wall chambers could account for the differences in temperature obtained.

\subsection{Physiological Loss in Weight (PLW)}

Significant $(\mathrm{p} \leq 0.05)$ variation in physiological loss in weight was observed among the three cooling chambers after the third days of storage period for both mangoes and sweet oranges (Tables 4 and 5). There was a sharp increase in physiological loss in weight of all 
Table 2. Cooling chamber temperature $\left({ }^{\circ} \mathrm{C}\right)$ over the storage period of Mangoes and Sweet Oranges at Melkassa, Ethiopia

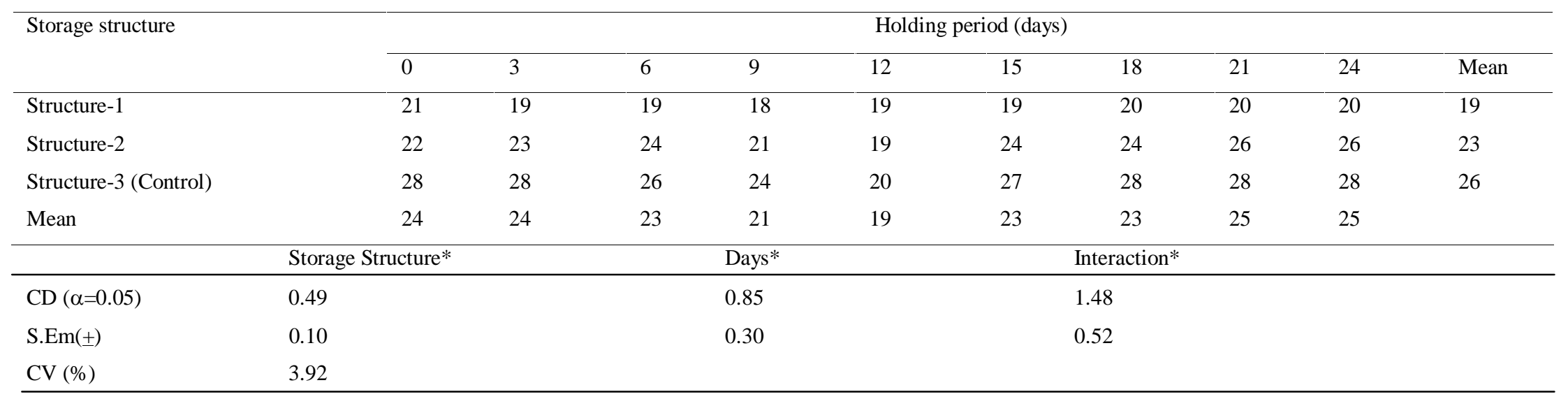

* Significant at $5 \%$ level of probability, CD = Critical difference, S.Em = Standard error of mean, CV= coefficient of variation

Table 3. Relative humidity (per cent) of cooling chambers over the storage periods of Mangoes and Sweet Oranges at Melkassa, Ethiopia

\begin{tabular}{|c|c|c|c|c|c|c|c|c|c|c|c|}
\hline \multirow[t]{2}{*}{ Storage structure } & & \multicolumn{10}{|c|}{ Holding period (days) } \\
\hline & & 0 & 3 & 6 & 9 & 12 & 15 & 18 & 21 & 24 & Mean \\
\hline Structure-1 & & 83 & 83 & 87 & 85 & 83 & 88 & 89 & 89 & 90 & 86 \\
\hline Structure-2 & & 72 & 76 & 71 & 75 & 73 & 76 & 78 & 81 & 82 & 76 \\
\hline Structure-3 (Control) & & 59 & 64 & 61 & 60 & 59 & 63 & 72 & 72 & 71 & 65 \\
\hline Mean & & 71 & 74 & 73 & 74 & 72 & 76 & 80 & 81 & 81 & \\
\hline \multicolumn{5}{|c|}{ Storage structure* } & \multicolumn{2}{|c|}{ Days* } & & \multicolumn{2}{|c|}{ Interaction* } & & \\
\hline $\mathrm{CD}(\alpha=0.05)$ & 1.11 & & & & \multicolumn{2}{|c|}{1.92} & & \multicolumn{2}{|c|}{3.32} & & \\
\hline S.Em (t) & 0.39 & & & & \multicolumn{2}{|c|}{0.67} & & \multicolumn{2}{|c|}{1.17} & & \\
\hline $\mathrm{CV}(\%)$ & 2.67 & & & & & & & & & & \\
\hline
\end{tabular}

* Significant at $5 \%$ level of probability.

$C D=$ Critical difference, $S . E m=$ Standard error of mean, $C V=$ Coefficient of variation. 
commodities stored in structure-3 (control), whereas, the increase in physiological loss in weight was found to be significantly ( $\mathrm{p} \leq 0.05$ ) less with regard to commodities stored in structure-1 as compared to the other structures. This could be attributed to the fact that the rate of respiration varied directly with temperature, (Edmond et al., 1957). This implied that the higher the temperature, the higher would be the respiration and moisture losses leading to weight loss and shrinkage.

It is also evident from regression line equations worked out that the physiological loss in weight of different commodities increased over holding time, but the rate of increment was almost double in structure-3 and structure-2, respectively as compared to structure-1 (Figures 2 and 3). Among the three cooling chambers irrespective of commodity, the slope of the regression line of the estimate was found to be less in structure-1. This clearly demonstrated that the rate of change of physiological loss in weight was greater in structure-3 and structure-2 per unit change of holding time. Strong linear relationship was observed between physiological loss in weight and progress in holding time irrespective of commodity ( $\mathrm{R}^{2}$ values approaching one). Significantly, lower physiological loss in weight values resulting from lower moisture loss recorded by horticultural commodities stored in structure-1 as compared to that of structure-2 and structure-3 (control). This could be attributed to the differences in temperature and relative humidity as influenced by thermodynamic properties of both the components as well as construction features of the storage structures (Anon, 1959; Sing et al., 1988). In the present study, ten per cent physiological loss in weight was considered as a threshold level for the termination of the shelf life. At this stage, the commodities presented good physical appearance with fruits stored in structure-1 in terms of attractive color, glossy appearance, having better edible qualities coupled with higher marketability. Based on these criteria, the physiological loss in weight of mango fruits in structure- 1 on the $9^{\text {th }}$ day of storage period was less by $34.98 \%$ as compared to the one in structure- 3 on the $6^{\text {th }}$ day of storage (Table 4 ).

Table 4. Effect of cooling chambers on physiological loss in weight, total soluble solids and volume of juice of mango fruits over storage period

\begin{tabular}{llllll}
\hline & & & \multicolumn{3}{c}{ Quality parameters } \\
\cline { 4 - 6 } S.No & \multicolumn{2}{c}{ Cooling chambers/Storage period } & PLW $(\%)$ & TSS $\left({ }^{0} \mathrm{~B}\right)$ & Juice $(\mathrm{ml} / \mathrm{kg})$ \\
\hline 1 & Structure-1 & 0-day & 0.00 & 11.00 & 599.7 \\
2 & Structure-1 & $3^{\text {rd }}$-day & 1.84 & 13.44 & 554.2 \\
3 & Structure-1 & $6^{\text {th }}$-day & 4.03 & 13.84 & 506.5 \\
4 & Structure-1 & $9^{\text {th }}$-day & 9.61 & 14.37 & 502.5 \\
5 & Structure-1 & $1^{\text {th }}$-day** & 13.72 & 14.33 & 486.4 \\
6 & Structure-2 & 0-day & 0.00 & 11.00 & 599.7 \\
7 & Structure-2 & $3^{\text {rd }}$-day & 2.41 & 14.33 & 528.8 \\
8 & Structure-2 & $6^{\text {th }}$-day & 8.44 & 14.43 & 489.2 \\
9 & Structure-2 & $9^{\text {th }}$ day** & 18.92 & 13.71 & 466.4 \\
10 & Structure-3 & 0 -day & 0.00 & 11.00 & 599.7 \\
11 & Structure-3 & $3^{\text {rd }}$-day & 2.62 & 14.56 & 536.0 \\
12 & Structure-3 & $6^{\text {th- }}$ day** & 14.78 & 14.89 & 453.6 \\
\hline \multicolumn{7}{c}{} & Test & $*$ & $*$ & $*$ \\
\hline & S.Em $(+)$ & & 0.75 & 0.30 & 11.03 \\
& CD $(\alpha=0.05)$ & 2.20 & 0.88 & 32.19 \\
\hline
\end{tabular}

* Significance at $5 \%$ probability level

**Indicate threshold level of physiological loss in weight in each cooling chamber.

$P L W=$ Physiological loss in weight

TSS $=$ Total soluble solids 


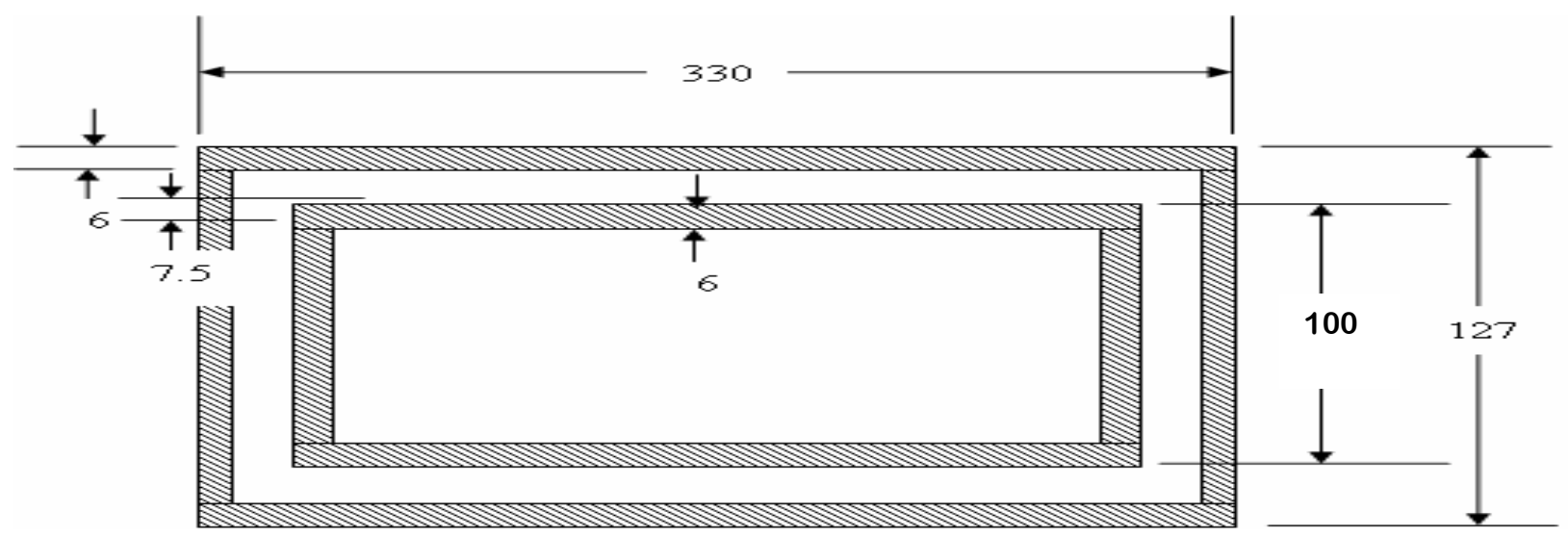

Note: All dimensions are in centimeters, drawing is not to scale.

Figure 1A. Schematic drawing showing plan view of structure-1/evaporative cooling and structure-2/mud-block chambers

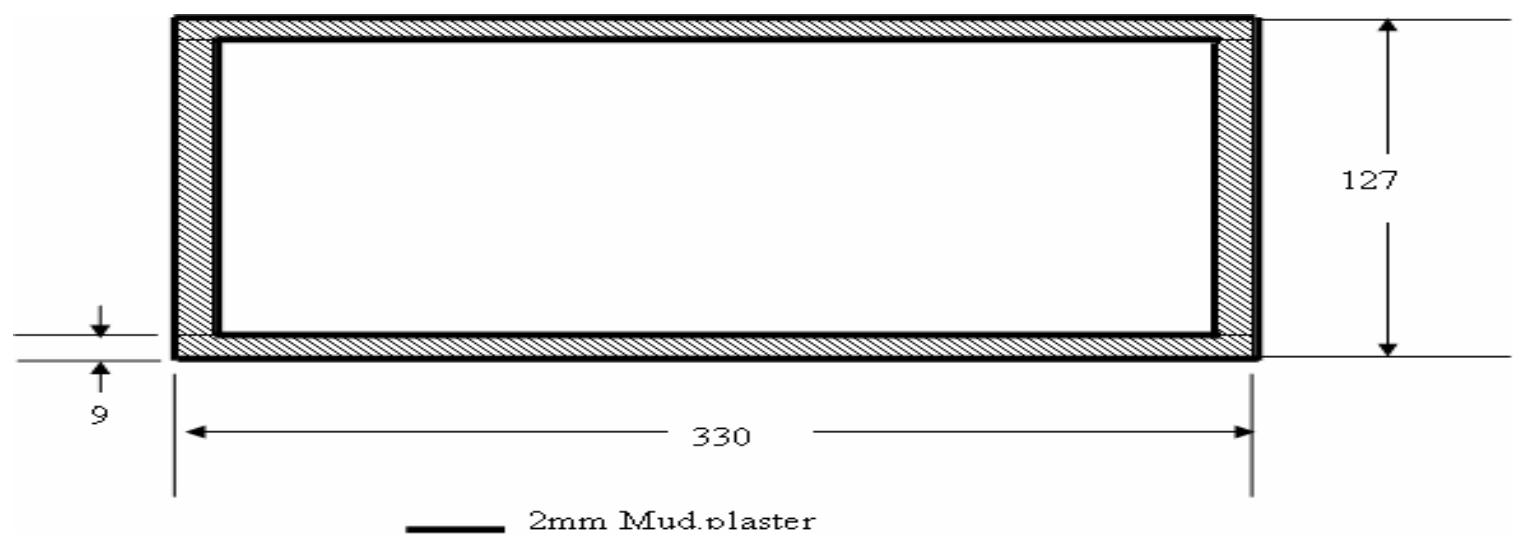

Note: All dimensions are in centimeters, drawing is not to scale.

Figure 1B. Schematic drawing showing plan view of structure-3/wooden wall chamber

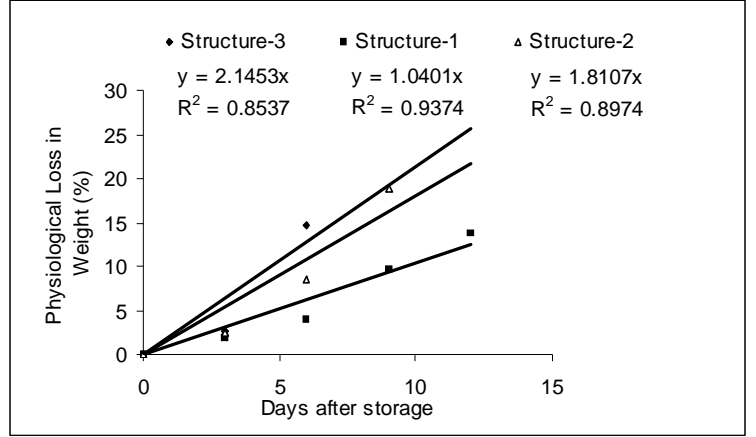

Figure 2. Effect of various cooling chambers on physiological loss in weight of Mango fruits over a storage period

Similarly physiological loss in weight of mango in structure- 1 on the $9^{\text {th }}$ day was less by $49.21 \%$ than that of the one in structure- 2 on the same holding time. This implied that structure-1 is more efficient in reducing the

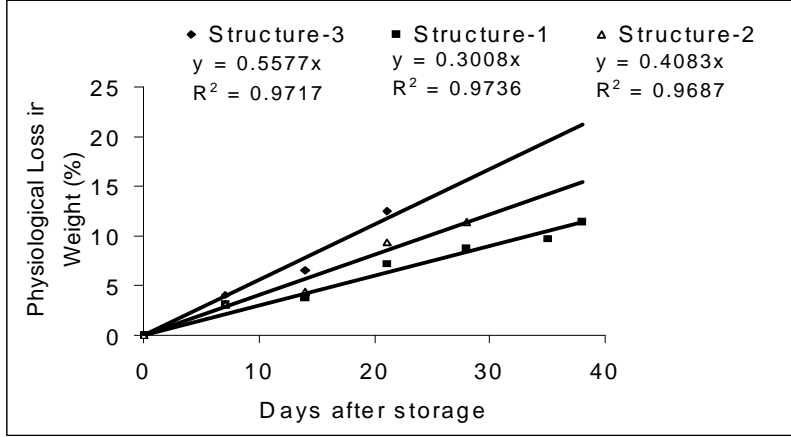

Figure 3. Effect of various cooling chambers on physiological loss in weight of sweet Orange fruits over a storage period

physiological loss in weight of mango fruits as compared to the ones stored in the other two structures at a given threshold level and over holding time. The efficiency of structure- 1 in significantly reducing the 
physiological loss in weight could also be attributed to the effect of low temperature obtained in the cooling chamber environment on the water vapor pressure within the commodity, which is a potential index for desiccation. (Thompson, 1985; 1992)

The threshold physiological loss in weight of ten per cent of mango fruit was attained within six days in structure-3 (control), after six days but before nine days in structure-2 and within twelve days for structure-1 (Figure 4). The significantly higher efficiency of structure-1 in extending the storability of mango fruits appears to be of considerable importance especially for such a climacteric fruit where in high respiratory climacteric leads to faster rate of senescence (Wills et $a l .$, 1998). The influence of structure-1 in lowering the temperature and increasing the relative humidity in the cooling chamber environments might have greatly contributed to an increased efficiency (Pal et al., 1997; Roy, 1988).

The lower slope of regression line equation than the other two chambers (Figure 2) also revealed the superiority of structure-1. The rate of change in physiological loss in weight per unit change of holding time was almost twice in structure- 3 and structure- 2 as compared to structure-1. The coefficient of determination $\left(\mathrm{R}^{2}\right)$ values showed the strong linear relationship between physiological loss in weight and progress in holding time. Structure-1 recorded significantly $(\mathrm{p} \leq 0.05)$ lower physiological loss in weight $(9.75 \%)$ for sweet oranges even after 35 days of storage as compared to the $21^{\text {st }}$ day of storage in structure-2 $(9.41 \%)$ and $(12.53 \%)$ in structure-3 (Table 5). This clearly indicated the superiority of structure-1 over the other structures for storage of sweet orange fruits

Table 5. Effect of cooling chambers on physiological loss in weight, total soluble solid and volume of juice of sweet orange fruits over storage period

\begin{tabular}{|c|c|c|c|c|}
\hline \multirow[b]{2}{*}{ S. No. } & \multirow{2}{*}{$\begin{array}{l}\text { Cooling chambers/ } \\
\text { Storage period }\end{array}$} & \multicolumn{2}{|c|}{ Quality parameters } & \multirow[b]{2}{*}{ Juice $(\mathrm{ml} / \mathrm{kg})$} \\
\hline & & PLW $(\%)$ & $\mathrm{TSS}\left({ }^{\circ} \mathrm{B}\right)$ & \\
\hline 1 & Structure-1 0-day & 0.00 & 8.36 & 571.6 \\
\hline 2 & Structure- $1 \quad 7^{\text {th }}$-day & 3.06 & 8.36 & 562.0 \\
\hline 3 & Structure- $1 \quad 14^{\text {th }}$-day & 3.77 & 8.76 & 543.6 \\
\hline 4 & Structure- $121^{\text {st }}$-day & 7.25 & 8.89 & 519.8 \\
\hline 5 & Structure-1 $28^{\text {th }}$-day & 8.72 & 9.28 & 508.7 \\
\hline 6 & Structure-1 $35^{\text {th }}$-day & 9.75 & 9.73 & 479.2 \\
\hline 7 & Structure-1 $38^{\text {th }}$-day** & 11.40 & 9.97 & 463.9 \\
\hline 8 & Structure-2 0-day & 0.00 & 8.36 & 571.6 \\
\hline 9 & Structure-2 $7^{\text {th }}$-day & 3.16 & 8.62 & 522.2 \\
\hline 10 & Structure-2 $14^{\text {th }}$-day & 4.32 & 8.97 & 512.6 \\
\hline 11 & Structure-2 $21^{\text {st }}$-day & 9.41 & 9.04 & 486.6 \\
\hline 12 & Structure-2 $28^{\text {th }}$-day** & 11.43 & 9.65 & 467.8 \\
\hline 13 & Structure-3 & 0.00 & 8.36 & 571.6 \\
\hline 14 & Structure-3 $\quad 7^{\text {th }}$-day & 4.02 & 8.90 & 520.3 \\
\hline 15 & Structure-3 $14^{\text {th }}$-day & 6.52 & 9.10 & 494.0 \\
\hline \multirow[t]{5}{*}{16} & Structure-3 $21^{\text {st }}$-day** & 12.53 & 9.42 & 456.4 \\
\hline & Test & $*$ & $*$ & $*$ \\
\hline & S.Em $( \pm)$ & 0.62 & 0.13 & 8.44 \\
\hline & $\mathrm{CD}(\alpha=0.05)$ & 1.80 & 0.37 & 24.31 \\
\hline & $\mathrm{CV}(\%)$ & 18.10 & 2.51 & 2.83 \\
\hline
\end{tabular}

*Significance at $5 \%$ probability level. **Indicate threshold level of physiological loss in weight in each Cooling chamber. PLW = Physiological loss in weight $\quad$ TSS $=$ Total soluble solids

Further, the fact that there were significant differences in effective holding times indicated that structure-1 could effectively store sweet orange fruits twenty days and fourteen days longer than structure- 3 and structure2 , respectively (Table 5 and Figure 3 ). Here again, the superiority of structure-1 in extending the shelf life could be attributed to the low temperature and high relative humidity obtained. The effective holding time observed also well compared with respect to the storage of sweet orange fruits using non-renewable energy sources to accomplish double the holding time (Burdon, 1997; Toledo, 1991). In view of this and the fact that structure-1 uses zero-energy in extending the shelf life of the commodities appears to be significant. The results presented in Figure 3 also explain that 
physiological loss in weight was found to be higher in structure- 3 and structure-2 than structure-1.

Based on threshold physiological loss in weight values of sweet orange fruits, least holding time (less than three weeks) was recorded in structure-3 and slightly beyond three weeks in structure-2 (Table 5). This further substantiated the utility of structure-1 for increasing the effective holding time to five weeks using no energy. This will have immense practical advantage for short-term storage of the commodity in remote rural areas by small and marginal farmers as well as by urban and semi-urban retailers not having access to energy sources.

\subsection{Total Soluble Solids ( ${ }^{\circ}$ Brix)}

There was a gradual increase in total soluble solids content of mangoes and sweet oranges studied over the holding time irrespective of the cooling chambers/structures used. This suggested the progress of ripening and senescence processes. In mango, it was observed that the rate of increment in total soluble solids under the influence of structure-1 was significantly $(\mathrm{p} \leq 0.05)$ lower on the $6^{\text {th }}$ day of storage as compared to structure- 2 and-3 (Table 4). This clearly brought out the superiority of structure-1 in slowing down of ripening process and extending the storability of mango over structure-2 and-3. The efficiency of structure-1 in slowing down ripening process could be attributed to the significant lowering of temperature and increase of relative humidity as compared to that of structure-3 (Tables 2 and 3). Similar views have been expressed by other works (Wasker et al., 1993).

The rate of increase in total soluble solids content of sweet orange under the influence of structure-1 was significantly $(\mathrm{p} \leq 0.05)$ lower than structure- 2 and-3 on the same day of holding i.e., twenty-first day of storage (Table 5). To determine the effective holding time, based on the threshold level of physiological loss in weight maximum total soluble solids was recorded on the $35^{\text {th }}$ day of storage in structure- 1 as compared to the $21^{\text {st }}$ day in structure- 3 . Thus, structure- 1 could provide incremental storage benefit of 14 days over structure-3. This is quite significant from the marketing point of view for both the farmers and retailers. Based on this analogy, structure-2 was also significantly less efficient than structure-1 as maximum total soluble solids content was recorded on the $28^{\text {th }}$ day of storage providing one week less time as compared to structure1 (Table 5).

\subsection{Juice Content}

The juice content of fruits and succulent of vegetables which is an important factor influencing the quality, generally decreased with the progress of storage (Wasker et al., 1993; Wasker et al., 1999). In the present study, mango fruits stored under structure-1 storage recorded significantly $(\mathrm{p} \leq 0.05)$ higher juice content $(6.74 \%)$ at twelve days of storage over that of structure 3 at the $6^{\text {th }}$ day though the fruits, based on physiological loss in weight criteria had crossed the threshold level (Table 4). This could probably be attributed to the low temperature and high relative humidity effects as factor of desiccation influencing water vapor pressure in the commodity (Thomson, $1985 ; 1992)$. In case of structure-2, the differences in juice content, however, was not significant ( $p \leq 0.05$ ) except for the effective holding time, which is also an important criterion of shelf life.

Structure-1 significantly $(\mathrm{p} \leq 0.05)$ influenced juice content of sweet orange fruits also, over holding times. The juice content of sweet orange after 35 days of storage in structure-1 was comparable to those in structure- 3 on the $14^{\text {th }}$ day of storage (Table 5). Thus, structure- 1 offered a potential advantage of almost three weeks an important consideration in the marketability of the commodity. The superiority of structure- 1 in this regard could be explained in light of the possible influence of low temperature and high relative humidity in lowering the water vapor pressure of the fruits which is a factor in maintaining the juice content (Thomson, 1985; 1992; Wills et al., 1998).

\section{Conclusion}

Structure-1 constructed from the factory pressed burnt clay performed best in extending the shelf life of mango and sweet-orange because of low temperature and high relative humidity over Structure- 2 constructed from locally molded mud block and Structure-3 constructed from wood. It is made from easily available materials and this may be scaled up with commercialization in order to suit the high demand from fruit growing community in different parts of Ethiopia. However, its adoption is limited to the area where water is not scarce to constantly keep the sand of interspaces moist.

\section{References}

Anonymous, 1959. Handbook of Air Conditioning Heating and Ventilating. The Industrial Press, 93 Worth, New York. pp.1-267.

ASHRAE. 1962. ASHRAE, Guide and Data Hand Book Applications. American Society of Heating, Refrigerating air-conditioning Engineers, Inc., New York. pp. 710-859.

Barre, H.J. and Sammet, L.L. 1959. Storage of Fruit and Vegetable Crops. Farm Structures, $4^{\text {th }}$ Printing, John Willey and Sons, Inc., New York and Hall Ltd., London, pp. 285-311.

Burdon, J. N. 1997. Post harvest Handling of Tropical and Subtropical Fruits for Export. Post harvest 
Physiology and storage of Tropical and Subtropical Fruits, Cab International, New York. pp.423.

Celis, J.E. and Stenning, B.C. 1997. Design and development of small container for controlled atmospheric storage. Agricultural Mechanization in Asia, Africa and Latin America 28 (2): 53-56.

Edmond, J. B., Musser, A. M. and Andrews, F.S. 1957. Fundamentals of Horticulture. $2^{\text {nd }}$ edition. McGraw-Hill Book Company, Inc. New York. pp.120-200.

Fekadu, T. 1991. Post-harvest Losses of Fruits and Vegetables in Horticultural State Farms, Ethiopia, Paper presented in First International Symposium on Horticultural Economics held at Alemaya, Ethiopia. pp. 261-270.

Gomez, K.A, and Gomez, A.A. 1984. Statistical Procedure for Agricultural Research, $2^{\text {nd }}$ edition. International Rice Research Institute. Wiley Interscience Publications, New York. pp.620.

Murata. 1997. Citrus. In: Mitra, S.K. (eds). Post-harvest Physiology and Storage of Tropical and Subtropical Fruits. CAB International, New York, USA. pp.21-40.

Pal, R. K., Roy, S. K. and Srivastava, S. 1997. Storage performance of Kinnow mandarins in evaporative cool chamber and ambient conditions. Journal of Food Science Technology 34 (3): 200-203.

Roy, S. K. and Pal, R.K. 1988. Zero energy cool chamber for maintaining post-harvest quality of carrots. Indian Journal of Agricultural Science 58 (9): 665-667.

Singh, K., Mann, S.S. and Mohan, C. 1988. Effect of fungicides and wax emulsion on storage of Kinnow mandarins at ambient conditions. Haryana Journal of Horticultural Science 117 (1 / 2 ): 14-19.

Thompson, J.F. 1985. Psychometrics and perishable commodities. In: Post-harvest Technology of Horticultural Crops. Co-operative Extension, University of California, Division of Agriculture and Natural Resources, USA.

Thompson, J. F. 1992. Storage Systems. Post-harvest Technology of Horticultural Crops, $2^{\text {nd }}$ edition. University of California, Publication 3311, Oakland, California.
Toledo, R. T. 1991. Fundamentals of Food Process Engineering, $2^{\text {nd }}$ edition. Chapman and Hall, an International Thomson Publishing Company, New York. pp. 425-436.

Waskar, D. P. and Garande, V.K. 1993. Post-harvest management of pomegranate in Maharashtra. Beverage Food World 24 (3): 26-28

Waskar, D. P., Khedkar, R. M. and Garande, V.K. 1999. Effects of post- harvest treatments onshelf life and quality of pomegranate in evaporative cool chamber and ambient conditions. Journal of Food Science Technology 36 (2) 114-117.

Wills, R., McGlasson, B., Gram D. and Joice, D. 1998. Post harvest, an Introduction to the Physiology and Handling of Fruits, Vegetables and Ornamentals, $4^{\text {th }}$ edition. UNSW Press Cab International New York. 